\title{
Intervención urbana y megaeventos en Río de Janeiro: resistencia de Vila Autódromo
}

a la política de remoción*

\section{Josiane do Vale Rafael Soares Gonçalves}

Pontificia Universidad Católica de Río de Janeiro, Brasil Recibido: 30 de junio del 2017 / Aprobado: 6 de septiembre del 2017 doi: 10.26439/limaq2018.n004.2254

El presente trabajo tiene como objetivo hacer un análisis sobre el periodo de preparación de la ciudad para la realización de los Juegos Olímpicos del 2016 y los impactos sociales resultantes de este proceso, especialmente en el caso de la favelaVila Autódromo, localizada en las proximidades del Parque Olímpico, lugar donde se concentraron la mayoría de las instalaciones deportivas para la realización de las competiciones. A pesar de estar ampliamente consolidada y con gran parte de sus habitantes con títulos de propiedad,Vila Autódromo fue removida, y en el lugar de sus cientos de casas se construyeron solamente 20 viviendas. A partir de las entrevistas con moradores y gestores públicos, se pretende comprender el largo proceso de la remoción de esta favela, analizar los intereses en pro de su remoción y la resistencia de los moradores.

Juegos Olímpicos, remoción de favelas, Río de Janeiro, Vila Autódromo

\section{Urban intervention and mega-events in Rio de Janeiro: Vila Autodromo resistance to the removal policy}

The present work aims to analyze this city preparation period for hosting the Olympic Games and the social impacts resulting from this process, especially in the case of the Vila Autodromo favela, located in the vicinity of the Olympic Park, the place where most of the sports facilities were concentrated as competition venues. Vila Autódromo was removed despite of being widely consolidated and of the fact that a large part of its inhabitants had a titled property, and only 20 houses were built in the place where there used to be hundreds of houses. We intend to understand the long process of this favela removal from the interviews with residents and public managers, analyzing the interests in favor of its removal and the resistance of its inhabitants.

Olympic Games, removal of favelas, Rio de Janeiro, Vila Autodromo

* Texto elaborado a partir de la investigación realizada para la sustentación de la tesis de maestría de la primera autora con la asesoría del segundo autor. Este trabajo contó con fondos del Consejo Nacional de Investigación (CNPq). 


\section{INTRODUCCIÓN: DEL DISCURSO DEL CAOS A LA CIUDAD OLÍMPICA}

La ciudad de Río de Janeiro es ciertamente uno de los casos más emblemáticos de los impactos que originan los grandes eventos internacionales para el planeamiento urbano. Probablemente, por primera vez en la historia, una ciudad fue sede de casi todos los eventos internacionales de gran visibilidad mundial. Esta dinámica comenzó remotamente con la Conferencia de la ONU sobre el Medio Ambiente, en 1992. Después de haber intentado, sin éxito, ser la sede de los Juegos Olímpicos del 2000 y del 2008, la candidatura de la ciudad de Río de Janeiro a los Juegos Panamericanos del 2007 fue aceptada y se configuró como un parteaguas. A partir de esa fecha, como fue analizado por Gonçalves (2013), la ciudad recibió todas las candidaturas en las que compitió: organizó los Juegos Militares del 2011, la última conferencia de la ONU sobre el medioambiente (Río+20), la Copa de las Confederaciones del 2013, las Jornadas Mundiales de la Juventud, también en el 2013, así como el Mundial de Fútbol del 2014 y los Juegos Olímpicos del 2016.

Los resultados obtenidos por la ciudad después de 10 años ininterrumpidos de organización y realización de grandes eventos no son nada alentadores. El estado de Río de Janeiro está completamente quebrado, por lo que debe a proveedores, está con inversiones paradas y pagos atrasados de salarios y pensiones. De la misma forma, la municipalidad anuncia recortes en el presupuesto para adecuarlo a la nueva realidad pos Juegos Olímpicos. Los gastos exorbitantes vinieron con acusaciones de una corrupción en toda la maquinaria pública, lo cual condujo al encarcelamiento del exgobernador Sergio Cabral y a toda la cúpula de su gobierno. Las investigaciones están alcanzando también a la maquinaria municipal. La violencia retomó los índices de una década atrás y causó que la ciudad fuera intervenida por tropas federales a fines de julio del 2017. El horizonte nebuloso que se dibuja es muy distante de la euforia que vivía la ciudad y el país cuando se hicieron los anuncios sucesivos de este lugar como sede de los eventos antes citados.

La conquista de estos eventos modificó completamente la forma de planear y administrar la ciudad, movilizó importantes recursos públicos y atrajo voluminosas inversiones privadas. Según Gonçalves (2014), se observó un importante repunte económico, que parecía vencer el auspicio del agotamiento económico y del aumento exponencial de la violencia. Las 
Unidades de Policía Pacificadora (UPP) redujeron los conflictos armados en las favelas y llevaron una supuesta sensación de seguridad a la población, aunque con el costo de la violación de los derechos humanos de los residentes de esas áreas, ya que el modus operandi violento de la policía no cambió. Río de Janeiro volvió a formar parte del centro económico y político del que se había alejado en las últimas décadas y mostró nuevamente su vocación de capital al ser más que nunca la vitrina internacional del país.

Tales eventos internacionales permiten la movilización de recursos y la elaboración de discursos orientados al resurgimiento de las ciudades, así como a la construcción de nuevas identidades locales. De acuerdo con Gonçalves (2014), a pesar de lo efimero de dichos eventos, estos dejan marcas importantes en las ciudades que son sedes y aseguran la legitimidad necesaria para importantes intervenciones urbanas. La concepción de la ciudad a partir de la organización de grandes eventos legitima políticas de emprendimiento urbano, colosales proyectos de renovación urbana y reitera la visión del espacio urbano como si estuviese vacío de memorias y significados. La pretendida importancia de los eventos para el futuro de la ciudad y el corto tiempo para prepararla han acabado justificando todo tipo de negociados e imponiendo un modelo consensuado de la ciudad sin el necesario debate.

Gonçalves (2014) describe que el espectáculo se presenta, partiendo de la reflexión de Guy Debord (1967), como un instrumento de unificación. Es necesario comprender que tales eventos son grandes espectáculos internacionales con una fuerte huella mediática para las ciudades que los reciben. Concebir la ciudad como un espectáculo implica la valorización de la imagen de esta a partir de modelos aceptados internacionalmente: la ciudad se vuelve una especie de producto que va a ser anunciado y comercializado. Así, se observa la construcción de una especie de imagen espacial que sería, según Michel Lussault (2007, p. 172), la relación entre una aparente visibilidad y un conjunto de significaciones. En el caso carioca, esta nueva economía semiótica urbana es excluyente, consolida espacios elitistas y pasteurizados, sin respeto por la diversidad urbana ni por la experiencia cotidiana de la población (Gonçalves, 2014).

El caso del modelo difundido al mundo de la ciudad de Barcelona es emblemático en lo que respecta a la producción de consensos. En conformidad 
con lo sustentado por uno de sus críticos más vigorosos, el antropólogo Manuel Delgado (2007, p. 16), el proyecto diseñado para Barcelona fue antes que nada un proyecto de mercado. Se trata de un auténtico paradigma de marketing urbano, una estrategia de promoción, difusión y comercialización cuyo objeto es la ciudad. Para evitar conflictos ante el aumento del costo de vida en una ciudad sede de grandes eventos, esta mercadería requiere, según Delgado (2007, p. 40), una adecuada combinación de teorización de las apariencias con un vocabulario debidamente marcado por invocaciones y valores abstractos del pensamiento políticamente correcto.

Así como el Río de Janeiro actual, Barcelona es el ejemplo de una alianza generalizada entre promotores inmobiliarios y administradores públicos. Este modelo se estableció a partir de alteraciones legislativas para el aumento de los patrones de edificabilidad, del uso recurrente de las fuerzas policiales para medidas de control urbano, de intervenciones de renovación urbana y recalificación de zonas consideradas abandonadas y degradadas, y finalmente de la mercantilización excesiva del suelo. Las intervenciones urbanas, como sustenta Delgado (2007, p. 48), suscitan un efecto dominó en el proceso de renovación urbana y permiten el avance exponencial de la especulación inmobiliaria. En fin, un proceso muy similar al que se observa actualmente en Río de Janeiro. En el caso carioca, hay que agregar la reanudación de las remociones de favelas, sobre todo en áreas de gran interés inmobiliario. Según datos del Comité de Seguimiento del Mundial y de los Juegos Olímpicos (2015), se removieron en la ciudad de Río de Janeiro entre el 2008 y el 2015 a alrededor de 22059 familias, sea por cuestiones de supuesto riesgo del local de residencia o por exigencias de las obras de preparación de la ciudad. Uno de los casos más emblemáticos fue el de Vila Autódromo tanto por la resistencia de sus moradores como por la insistencia de la municipalidad en retirarlos de allí, como se verá a continuación.

\section{LA ELITIZACIÓN DEL ESPACIO URBANO: El PROYECTO PARQUE OLÍMPICO Y VILA AUTÓDROMO}

La noción de ciudad-espectáculo implica la reorganización de una nueva visibilidad urbana que permita atraer los capitales internacionales. Para 
esto, es necesario forjar una nueva visión de ciudadanía. La participación popular es valorizada en el discurso, pero no es caracterizada en la práctica. El espectáculo, según Gonçalves (2014, p.18), encuadra la participación y sugiere un consenso, aunque la dinámica de la organización del espectáculo promueva medidas contrarias a la población y viole los derechos, sobre todo de los más pobres. Existe una fuerte gestión de las fuerzas locales a través de asociaciones público-privadas, de la valorización del emprendimiento urbano, de las supuestas mejoras de la calidad de vida con nuevas inversiones en equipamiento urbano, de la construcción de un patriotismo local y eventualmente a través de una mayor oferta de trabajo por cierto periodo.

Si el espectáculo pauta la recepción de recursos y la movilización de la población, entonces el planeamiento urbano se ve condicionado por modelos urbanos aceptados internacionalmente, como se citó del modelo Barcelona. El espacio urbano pasa a ser concebido solamente como forma, como una agrupación de objetos y no como forma-contenido, como un sistema de objetos y acciones. Las nuevas imágenes difundidas de la ciudad se ofrecen para construir nuevas prácticas sociales con el fin de suscitar un conjunto de valores, sintetizar nuevas formas de ser y de vivir en el espacio urbano. Tal proceso implica una simplificación de la imagen de la ciudad que refleja los intereses y modelos de las clases dominantes, y que procura reconstruir la identidad urbana a través de la omisión de grupos, prácticas y espacios.

Los grandes eventos internacionales son la justificación precisa para emprender grandes renovaciones urbanas y presentan una fuerte ideología que busca consolidar consensos en torno a la imagen del resurgimiento urbano. Sin embargo, estos discursos enmascaran las consecuencias concretas de las intervenciones urbanas al invisibilizar a ganadores y perdedores en el transcurso del proceso. Según Smith (2006, p. 61), el lenguaje coherente del renacimiento urbano es la prueba de la generalización de la gentrificación en el paisaje urbano. En la propia noción de revitalización o de renovación, como analiza Sánchez (2009, p. 179), se sugiere que el gestor/planeador sería creador de la vida social, y subraya que las características pretéritas locales no estarían de acuerdo con los contenidos deseables para el nuevo proyecto de ciudad.

Vila Autódromo fue una de las varias favelas que sufrieron el proceso de remoción, pero su caso obtuvo una gran repercusión por la movilización 
de sus moradores. La favela se localiza en el área limítrofe entre los barrios de Jacarepaguá y Barra da Tijuca, zona de fuerte interés para el mercado inmobiliario por la posibilidad de expansión y valorización inmobiliaria. El barrio de Barra da Tijuca es conocido por la presencia de centros comerciales, así como de grandes condominios que tienen en su interior tiendas, gimnasios, áreas de esparcimiento, entre otros servicios destinados a la clase media alta. Según Silva (2004), Barra da Tijuca surgió como una extensión de la Zona Sur, área acomodada de la ciudad, ya que gran parte del suelo de esta región ya estaba agotada. De acuerdo con Gaffney (2013), entre el 2007 y el 2010, la mayoría de los proyectos inmobiliarios de la ciudad de Río de Janeiro se destinaron a Barra da Tijuca, lo que demuestra la importancia del barrio para el mercado inmobiliario. La ausencia de políticas habitacionales, el deficiente sistema de transporte y la gran oferta de empleos en los condominios y shopping centers acarrearon el crecimiento de las favelas de la región. Debido a su localización,Vila Autódromo sufrió diversas tentativas de remoción, lo que se consiguió finalmente en la víspera de la apertura de los Juegos Olímpicos.

De acuerdo con el informe elaborado por el Grupo de Trabajo Académico Profesional Multidisciplinario (GTAPM, 2013) ${ }^{1}$, en la década de 1960 la región fue elegida para que se construyera el Autódromo de Jacarepaguá, pero como se hallaba cerca de una laguna, el área tuvo que ser aterrada. Con el aterramiento alrededor de la laguna, los pescadores se instalaron en la década de 1970 y dieron inicio a la formación de Vila Autódromo. El crecimiento de la favela siguió al desarrollo de los barrios adyacentes. Al final de la década de 1980, se creó la Asociación de Moradores, Pescadores y Amigos deVila Autódromo (Ampava), que tenía como objetivo defender los intereses de la favela, como por ejemplo, el acceso a servicios básicos: agua, energía eléctrica, documentación, entre otros. Aun al final de esa década, la municipalidad reasentó a familias retiradas de otra favela cercana a Vila Autódromo, por lo que aumentó el número de habitantes en el lugar.

1 El GTAPM fue constituido por integrantes de diversas instituciones de distintas áreas con el objetivo de elaborar un informe técnico sobre las verdaderas condiciones de Vila Autódromo al confrontar los proyectos de la municipalidad con los de los moradores. Opinión disponible en http://lemetro. ifcs.ufrj.br/gtapm_parecer_2013.pdf. Accedido el 15 de junio del 2017. 
Según el GTAPM (2013), dado que las tierras le pertenecían al Gobierno del Estado, este confirió a los habitantes el título de concesión de derecho real de uso $^{2}$ (CDRU) durante la década de 1990 y declaró el área, en el 2005, de especial interés social ${ }^{3}$. A pesar de estar respaldados jurídicamente, los habitantes de Vila Autódromo comenzaron a sufrir la amenaza de remoción desde la década de 1990. En 1993, el entonces subprefecto de Jacarepaguá y de Barra da Tijuca, Eduardo Paes (que se convirtió en el alcalde entre el 2009 y el 2016, y fue uno de los responsables de la realización de los Juegos Olímpicos en la ciudad) gestionó una acción civil pública, en la que defendía la remoción de la favela por considerar que esta causaba daño urbano, estético y ambiental. En 1996, la ciudad de Río de Janeiro fue perjudicada por intensas lluvias que terminaron con muertos y un gran número de damnificados. Este contexto sacó nuevamente a colación la discusión sobre la necesidad de remoción de las favelas, inclusive la de Vila Autódromo, por ser consideradas una supuesta área de riesgo.

Este espacio fue por muchos años el autódromo de la ciudad de Río de Janeiro y, a pesar de la perspectiva de valorización inmobiliaria de la zona, Vila Autódromo era uno de los pocos centros habitados. Allí se observaba una reserva importante de tierras con la posibilidad de proyectos inmobiliarios futuros. La perspectiva del uso del lugar como una nueva frontera inmobiliaria se vislumbró con la elección de Río de Janeiro en el 2002 como sede de la edición de los $15 .^{\circ}$ Juegos Panamericanos, motivo por el que la favela fue nuevamente blanco del discurso de remoción, sobre todo porque parte de las instalaciones de los Juegos Panamericanos se ubicaban en el Autódromo de Jacarepaguá como una estrategia de la municipalidad para hacer de esta área el principal sector de los Juegos Olímpicos.

2 "Mediante la concesión de derecho real de uso, la administración pública puede ceder el uso de bienes de su dominio para el particular, de forma remunerada 0 gratuita, por tiempo fijo 0 indeterminado, bajo la forma de derecho real resoluble, para el desarrollo e implementación de actividades socioeconómicas que sean relevantes para el interés público" (França, 2006, p. 1).

3 "Área de especial interés social -AEIS es aquella destinada a programas habitacionales de interés social - HIS, destinados prioritariamente a familias de ingresos iguales o inferiores a los seis salarios mínimos, de promoción pública o a ella vinculada, admitiéndosele usos de carácter local complementarios al residencial, tales como comercio, instalaciones comunitarias de educación y salud y áreas de deporte y recreación" (Plan Director, 2013). 
Paralelamente al proceso de remoción, diversas obras estaban ejecutándose en las proximidades de Vila Autódromo. Se construyó un corredor expreso de ómnibus, llamado BRT (Bus Rapid Transit), que conectaba las instalaciones olímpicas de Barra da Tijuca con otras instalaciones en el barrio de Deodoro. Al lado de la favela se levantaron el Parque Olímpico y dos edificaciones que fueron usadas como centro de medios durante la realización de los Juegos Olímpicos, para posteriormente convertirse en un local comercial. Según Renato Cosentino Vianna Guimarães (2015), el Consorcio Río Más, formado por las constructoras Odebrecht, Andrade Gutierrez y Carvalho Hosken, fue el responsable de la construcción de las instalaciones deportivas y del alojamiento para los atletas. Después de los Juegos, el consorcio recibió de la municipalidad un área de aproximadamente $1180000 \mathrm{~m}^{2}$ para levantar edificios residenciales, centros comerciales y hoteles. Se trata de un área pública que la municipalidad traspasó a la iniciativa privada, a través de una asociación público-privada, y que engloba también el área ocupada porVila Autódromo.

\section{LA LUCHA CONTRA LA REMOCIÓN DE VILA AUTÓDROMO}

La realización de los Juegos Olímpicos del 2016 posibilitó que el poder público removiera a innumerables familias de Vila Autódromo. Según datos de la municipalidad ${ }^{4}$, de las casi 800 familias residentes en el local, solo 20 permanecieron. Aunque el proyecto vencedor para el Parque Olímpico en el local previó la permanencia de la favela y su urbanización, la municipalidad presentó diversas justificaciones para la remoción de Vila Autódromo, como la urgencia de un perímetro de seguridad para las instalaciones de los Juegos Olímpicos, la necesidad de ensanchamiento de las vías próximas y hasta alegó riesgo ambiental por la proximidad de las casas a la laguna de Jacarepaguá.

Según Mario Brum (2013), el entonces alcalde Eduardo Paes adujó que Vila Autódromo se encontraba cerca de un área que tenía protección ambiental y que, por esta razón, el título de posesión concedido anteriormente no era válido. A pesar de este argumento, la ejecución de obras por parte de

4 (http://www.río.rj.gov.br/dlstatic/10112/5977874/4156506/vilaautodromo2.pdf). Accedido el 15 de junio del 2017. 
la municipalidad para los Juegos Olímpicos deforestó zonas que deberían estar protegidas por leyes ambientales, como fue el caso de las áreas donde se construyeron el campo de golf y el corredor vial Transolímpica. Solo este último preveía la destrucción de $200000 \mathrm{~m}^{2}$ de Mata Atlántica ${ }^{5}$. Gonçalves y França (2010) afirman que el discurso ambiental es apropiado de forma diferente si el foco es la favela o si son emprendimientos de mayor lucro. La flexibilización de las normas urbanísticas presenta un carácter elitista porque promueve la expulsión de la población pobre de las áreas de interés, principalmente para favorecer al mercado inmobiliario.

En el intento de revertir la decisión de remoción, los habitantes buscaron el apoyo de grupos procedentes de las universidades públicas y elaboraron un plan de urbanización, el Plan Popular deVila Autódromo ${ }^{6}$. En este se proponía, como alternativa a la remoción, la urbanización de la favela, que tendría un costo más reducido si se comparaba con la remoción y reasentamiento de los pobladores, planteado por la municipalidad. El alcalde se reunió con algunos moradores y prometió analizar el plan elaborado para Vila Autódromo y divulgar una postura. Sin embargo, los moradores jamás obtuvieron una respuesta sobre esta propuesta. El proceso de remoción se inició sin que los pobladores participasen en los espacios de decisión y sin que se considerasen sus propuestas, lo que definió una acción autoritaria de la municipalidad.

Para entender cómo se dio el proceso de remoción, entrevistamos a algunos moradores, quienes describieron las acciones realizadas por la municipalidad. Según indican, supieron que serían desalojados a través de los diversos medios:

5 Sobre el campo de golf, leer el dosier sobre las violaciones del derecho al deporte ya la ciudad (http:// www.observatoriodasmetropoles.net/images/abook file/dossie violacoesesporte rio2015.pdf). Accedido el 15 de junio del 2017. Sobre la construcción de Ta Transolímpica, Teer el artículo divulgado en el sitio web UOL (https:/esporte.uol.com.br/rio-2016/ultimas-noticias/2014/04/15/ obra-de-avenida-olimpica-do-rio-vai-derrubar-200-mil-m-de-mata-atlantica.htm). Accedido el 15 de junio del 2017.

6 El Plan Popular de Vila Autódromo fue elaborado por los moradores de Vila Autódromo con el apoyo del Instituto de Investigación y Planeamiento Urbano Regional de la Universidad Federal de Río de Janeiro (IPPUR/UFRJ) y del Centro de Estudios y Proyectos Habitacionales y Urbanos de la Universidad Federal Fluminense (NEPHU/UFF). (Asociación de Moradores y Pescadores de Vila Autódromo, 2012). 
televisión, diarios, redes sociales, entre otros. El primer contacto que tuvieron con representantes de la municipalidad fue por medio de los equipos que pasaban por la zona para realizar la inscripción de las familias y la medición de las casas. Estos equipos presentaban un discurso coercitivo en el que todos serían desalojados.

Muchos habitantes rechazaron inscribirse justificando que tenían el derecho de permanecer y se movilizaron para convencer a otros moradores de resistir. Junto con diversos grupos de apoyo (académicos, militantes, políticos), Vila Autódromo presentó una fuerte resistencia contra la remoción.

De acuerdo con los relatos de los pobladores, una de las estrategias de la municipalidad para desarticular el movimiento de resistencia fue la negociación individual con los moradores y la cooptación de algunos para convencer a los demás de negociar con la municipalidad. Al inicio, con el movimiento de resistencia no consolidado, las familias desalojadas no tuvieron un poder de negociación mayor con la municipalidad, así que optaron por recibir una indemnización monetaria o un departamento en un conjunto habitacional erigido por la municipalidad. Con la intensificación del movimiento de resistencia y la disminución de plazos para la realización de los Juegos Olímpicos, la municipalidad empezó a entablar negociaciones más ventajosas para los habitantes, con indemnizaciones con valores más altos; asimismo, algunas familias llegaron a recibir indemnizaciones y departamentos. Supimos de casos de familias que recibieron más de un departamento y que cada inmueble fue registrado a nombre de sus diferentes miembros.

Con la finalidad de recibir a los moradores removidos de Vila Autódromo, la municipalidad construyó un conjunto habitacional con 900 apartamentos distribuidos en cuatro condominios, llamado Parque Carioca ${ }^{7}$, situado a 1,5 km de Vila Autódromo. Sus principales atractivos eran las áreas de recreación, a imagen de los condominios de la clase media de la región. Actualmente, se han suscitado diversas quejas sobre la calidad de estas construcciones ${ }^{8}$.

7 Accedido el 15 de junio de 2017. Proyecto disponible en http:/www.rio.rj.gov.br/ dlstatic/10112/3641881/DLFE-267980.pdf/Apresentacao_Parque_Carioca_2.0.1.3..pdf.

8 Accedido el 15 de junio del 2017. Denuncias publicadas en http://rioonwatch.org.br/?p=20108 
Azevedo y Faulhaber (2015) constataron que la mayoría de las personas procedentes de las favelas removidas eran reasentadas en lugares distantes de su vivienda anterior, principalmente en la zona oeste de la ciudad, sector alejado del centro de la urbe y de la zona sur, lo que caracterizó la remoción como un instrumento de segregación espacial. A diferencia de estos casos, las familias removidas de Vila Autódromo fueron destinadas a un conjunto habitacional próximo al lugar. Esto fue ciertamente el resultado del arduo movimiento de resistencia engendrado por los moradores y sus simpatizantes.

Además de la negociación de forma individualizada, la municipalidad utilizó la presión psicológica, a través de innumerables llamadas telefónicas, para que los pobladores aceptasen desalojar sus casas. A medida que las familias salían de sus casas, la municipalidad inmediatamente demolía las viviendas y no retiraba los escombros en un intento de imposibilitar la permanencia de los demás moradores que estaban resistiendo el desalojo. La estrategia de la municipalidad era fomentar el caos y hacer inviable la vida en la favela. El local, otrora consolidado, fue paulatinamente destruido por la municipalidad, que dejaba los escombros y no efectuaba reparaciones adicionales en los servicios de agua y luz. A través de una determinación judicial, accionada por el Centro de Tierras y Habitación de la Defensoría Pública de Río de Janeiro, la municipalidad fue obligada a retirar por lo menos el desmonte, pues en caso contrario sería multada.

Los pobladores percibieron que al mismo tiempo que las casas eran medidas y registradas, las familias comenzaban a recibir propuestas de negociación, personalmente o por teléfono, y eran bastante acosadas para hacer la negociación con la municipalidad. Las casas que no eran medidas permanecieron en pie. Estratégicamente, muchos habitantes recusaron el registro y no permitieron que los funcionarios entrasen en sus viviendas. Muchas de estas fueron registradas solamente después de una decisión judicial tras una acción legal promovida por la municipalidad.

A través de un decreto de expropiación, la municipalidad definió las casas que deberían ser demolidas y dejó recelosos a los pobladores que aún ofrecían resistencia. Al descubrir que sus casas constaban en este decreto, muchos moradores salieron del movimiento de resistencia por temor a no conseguir una indemnización satisfactoria y negociaron directamente con la 
municipalidad, ya que el avalúo realizado por medida judicial era inferior al que la municipalidad ofrecía. En ese momento, ya pocas familias persistían en la resistencia.

Además de los pobladores, entrevistamos también a asistentes sociales que, de alguna forma, estuvieron involucradas en el proceso de desalojo, especialmente de Vila Autódromo. A través de estas entrevistas, constatamos que la municipalidad orientaba a los diversos profesionales para tener una actitud persuasiva con los habitantes con la intención de convencerlos de salir de la localidad. Había metas diarias de registros que debían realizarse. Por otro lado, los datos proporcionados a los moradores por la municipalidad nunca eran claros y, a veces, contradictorios. La falta de información era una estrategia de acción que dificultaba las formas de movilización política. Uno de los pobladores nos relató que muchos no aguantaron el proceso de remoción:

No todos soportan este movimiento de desalojo. Mucha gente se puso mal, los ancianos se pusieron mal. La municipalidad es muy perversa. Nos dejaron en un escenario de guerra, una presión psicológica y con violencia física. Llamadas constantes a los pobladores. Después que la casa era medida, recibía llamadas constantemente. Había pobladores que recibían 15 llamadas por día. ¡Un acoso! Tocaban tu puerta, llamaban... Después que medían la casa, se volvía un infierno. Decían que aun midiendo nadie sería obligado a salir. Medir ya era una estrategia. Comenzaban las llamadas, las peleas familiares, muchas familias se fragmentaron, parejas se separaron, algunas familias para no separarse, alguien tenía que ceder, y generalmente quien cedía era para salir?

El proceso se realizó de forma truculenta, con la participación de la Guardia Municipal principalmente en los desalojos. Fueron diversos los casos de conflicto entre la guardia y los pobladores, que resultaron muchas veces en la agresión física contra estos últimos.

Debido al movimiento de resistencia, Vila Autódromo obtuvo el apoyo de grupos de la sociedad civil, de universidades públicas y particulares, de los medios alternativos y el apoyo internacional. Según los propios habitantes,

9 Morador 1. Entrevista realizada en agosto del 2016. 
personas que también pasaron por el proceso de remoción en sus países a causa de la organización de megaeventos deportivos enviaron mensajes de solidaridad. Fue gracias al movimiento de resistencia que Vila Autódromo continuó existiendo. Para las 20 últimas familias que permanecieron en el local, la municipalidad elaboró un plan de urbanización que preveía la construcción de casas contiguas, una para cada familia, además de una escuela, área de recreación, desagüe, iluminación, pavimentación, paisajismo y veredas. Los pobladores reclamaron que este proyecto fue elaborado sin consultarles y divulgado primero a la prensa, en lugar de dárselo a ellos, los principales interesados. Tras las reivindicaciones, los moradores se reunieron con el alcalde y le exigieron cambios en el proyecto, como la construcción de un patio alrededor de cada casa, en vez de casas contiguas, que era la propuesta de la municipalidad, un detalle que para ellos era considerado muy importante. Esto demuestra que la lucha y la organización de los pobladores fueron importantes desde el inicio hasta el final del proceso de remoción.

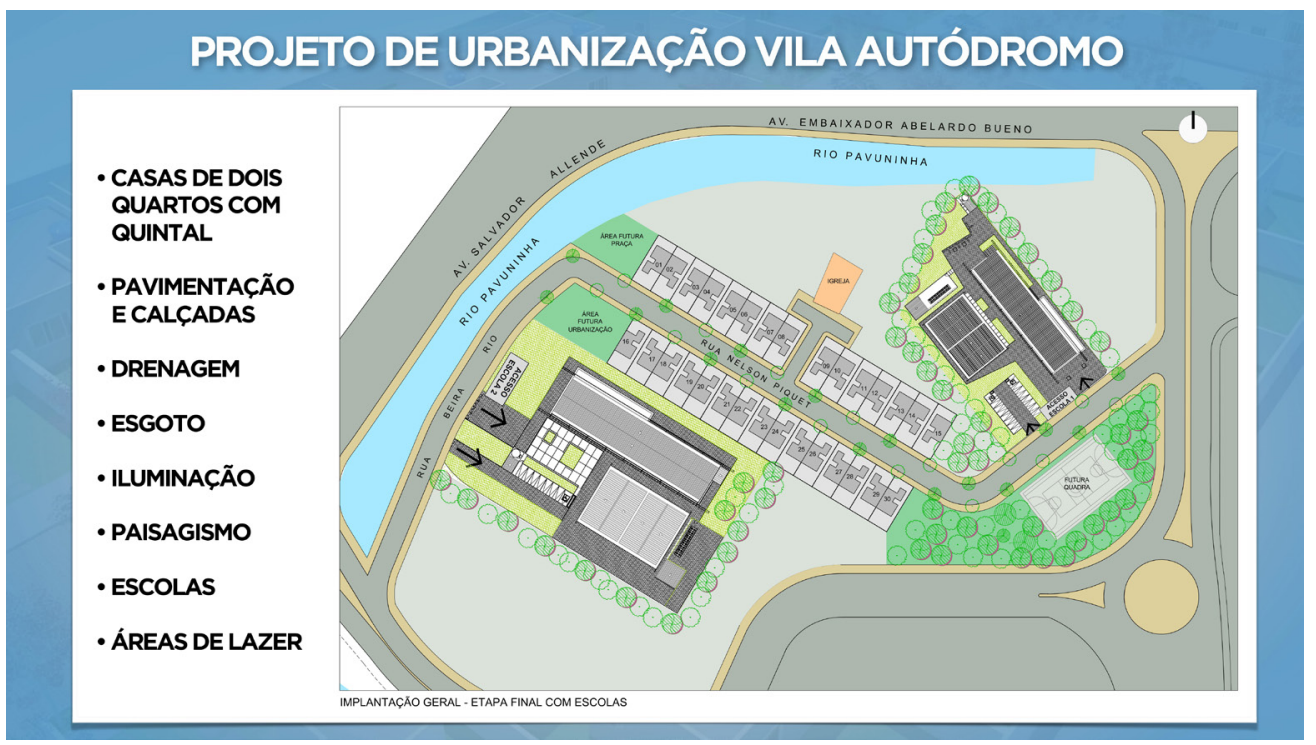

Figura 1

Proyecto propuesto por la Municipalidad de Río de Janeiro

Fuente: https://riorealblog.files.wordpress.com/2016/03/vila-autodromo2.pdf 
Las casas fueron construidas y entregadas en julio del 2016, un mes anterior al inicio de los Juegos Olímpicos. A pesar de permanecer en el lugar, estos moradores nos relataron que el proceso de remoción afectó también las relaciones sociales entre familiares y entre vecinos. Muchos hogares se dividieron porque sus miembros no se ponían de acuerdo entre resistir o aceptar la oferta de la municipalidad. Uno de los pobladores entrevistados nos relató que perdió el vínculo con parientes y antiguos vecinos por continuar resistiendo a la remoción.

Otro de los reclamos de los moradores fue la construcción de un espacio destinado al Museo de las Remociones, según el folleto bilingüe (figura 2) distribuido por ellos:

El Museo nació de la articulación entre los pobladores de Vila Autódromo y sus simpatizantes. Su objetivo es registrar la historia de violencia, pero también de luchas, que ocurrieron en los últimos años. Tal experiencia surge de la necesidad de enfrentar el doble proceso de borrado buscado por las prácticas estatales: tanto del espacio fisico como de las redes de relaciones (afectivas, morales, políticas y económicas) que formaron históricamente a la comunidad. Este Museo es más un acto de resistencia deVila Autódromo. iLa memoria no se remueve! [cursivas del autor].

El objetivo del Museo de las Remociones es que se lleven a cabo trabajos académicos, reportajes y otras producciones que cuenten de alguna forma la historia deVila Autódromo, principalmente durante el proceso de remoción. Durante las remociones, los moradores organizaron muchos debates y eventos culturales, que suceden hasta el día de hoy. El Museo de las Remociones se inserta, así, en el esfuerzo de varios movimientos de las favelas para crear museos sociales y hacer de la memoria una herramienta política. A pesar de la destrucción casi completa de Vila Autódromo, la idea es mantener viva la memoria de este lugar y las luchas de sus habitantes por la consolidación de una ciudad más justa e incluyente. 


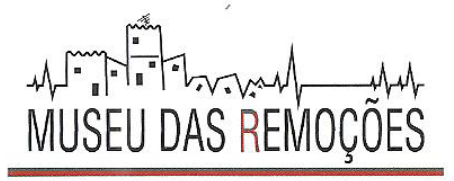

O Museu das Remoções é um museu a céu aberto na Vila Autódromo. O museu atua em intervenções artísticas, principalmente no território da Vila; na realização de oficinas culturais; e em uma vasta pesquisa sobre o local em acervos pessoais dos moradores e apoiadores, na imprensa, nas mídias sociais e na produção acadêmica.

O Museu nasceu da articulação entre os moradores da Vila Autódromo e seus apoiadores. Seu objetivo é registrar a história de violências, mas também de lutas, que ocorreram nos últimos anos. Tal experiência surge da necessidade de enfrentar o duplo processo de apagamento buscado pelas práticas estatais: tanto do espaço físico quanto das redes de relações (afetivas, morais, políticas e econômicas) que formaram historicamente a comunidade. Este Museu é mais um ato de resistência da Vila Autódromo. Memória não se remove!

The Evictions Museum is an open air museum in the favela of Vila Autódromo. It is run through artistic interventions, principally within Vila Autódromo, through cultural workshops, and through research into the area using records from residents and their supporters, newspapers, social media and academic reports.

The museum is the product of dialogue between residents of Vila Autódromo, and supporters of their struggle. Its objective was to record the violence, but also the resistance, that took place in the community over the last few years. These experiences have shown the importance of standing up to the processes of erasure carried out by the state. This erasure applies to both the physical space and the networks of relations (emotional, moral, political, economic) which have formed the community over time. This museum is yet another act of resistance by VilaAutódromo. Memory is something that won't be evicted!

@museudasremocoes

Figura 2

Folleto distribuido por los moradores de Vila Autódromo, en visita realizada en agosto del 2016 


\section{CONSIDERACIONES FINALES}

Río de Janeiro se encuentra en una situación muy diferente de la que fue anunciada por autoridades y empresarios con la realización de los Juegos Olímpicos. Contrariamente a los discursos de desarrollo económico y social, la ciudad se halla en una grave crisis económica, con el aumento del desempleo, de los índices de violencia y de la sensación de abandono por el poder público. No se puede atribuir toda la crisis a la realización de estos megaeventos, pero es posible afirmar que el ciclo de preparación de la ciudad contribuyó a agravarla, dado que se destinaron voluminosas inversiones públicas para su ejecución.

Estas inversiones fueron dirigidas de acuerdo con la lógica del mercado, en perjuicio de las necesidades reales de la mayor parte de la población carioca. Las intervenciones urbanas privilegiaron áreas con gran potencial de valorización, importantes principalmente para el mercado inmobiliario. Se pretendió crear las condiciones ideales de acumulación, lo cual benefició a determinados sectores del mercado. La ciudad fue concebida como una empresa y mercadería, orientada por el y hacia el mercado (Vainer, 2000g).

Una de las grandes marcas de las intervenciones urbanas en este contexto fue la remoción de innumerables favelas del escenario urbano carioca y la transferencia de los moradores hacia áreas distantes de la ciudad. Esto permitió la liberación de tierras ocupadas por estas viviendas y contribuyó a una mayor valorización de las áreas adyacentes. La remoción deVila Autódromo fue con seguridad el caso modelo de una forma de planeamiento urbano elitista y segregador de un Río de Janeiro olímpico.

\section{REFERENCIAS}

Associação de Moradores e Pescadores da Vila Autódromo. (2012). Plano popular da Vila Autódromo. Plano de desenvolvimento urbano, econômico, social e cultura. Recuperado de https://comitepopulario. files.wordpress.com/2012/08/planopopularvilaautodromo.pdf

Azevedo, L., y Faulheber, L. (2015). SMH 2016:Remoções no Rio de Janeiro olímpico. Río de Janeiro: Mórula. 
Brum, M. (2013). Favelas e remocionismo ontem e hoje: da ditadura de 1964 aos grandes eventos. O Social em Questão, (29).

Comitê Popular da Copa e Olimpíadas do Rio de Janeiro. (2015a). Dossiê Megaeventos e Violações dos Direitos Humanos no Rio de Janeiro: Olímpiadas Rio 2016, os jogos da exclusão. Río de Janeiro.

Comitê Popular da Copa e Olimpíadas do Rio de Janeiro. (2015b). Rio 2016: um legado de violaçaões. Dossiê das violações do direito ao esporte e à cidade: cadê o legado esportivo da Olimpíada do Rio de Janeiro. Recuperado de http://www.observatoriodasmetropoles.net/ images/abook_file/dossie_violacoesesporte_rio2015.pdf

Debord, G. (1967). La Sociètè du spectacle. París: Champ Libre.

Delgado, M. (2007). La ciudad mentirosa, fraude y miseria del "modelo Barcelona". Madrid: Catarata.

Franca, V. R. (2006). Temas diversos sobre a concessão de direito real do uso celebrada por sociedade de economia mista. Revista de Informação Legislativa 43(171), 225-232.

Gaffney, C. (2013). Forjando os anéis: a paisagem imobiliária pré-olímpica no Rio de Janeiro. E-Metrópolis, (14).

Gonçalves, R. S. (2013). O espetáculo da paisagem carioca, novas configurações urbanas e seus espaços sociais. In M. de F. Cabral Marques Gomes, R. Santos Maia, I. C. da Costa Cardoso y B. Alves de França (orgs.). Renovação urbana, mercantilização da cidade e desigualdades socioespaciais. Río de Janeiro: Mauad X.Gonçalves, R. S. (2014). Do Centenário à Olimpíada: megaeventos e seus impactos sociais na cidade do Rio de Janeiro em uma perspectiva histórica. Revista Praia Vermelha, 24(1), 17-41.

Gonçalves, R. S., y França, B. A. (2010). Entre o muro e a remoção: meio ambiente e favelas no Rio de Janeiro. En M. F. Cabral Marques Gomes y M. J. Barbosa (Eds.), Cidade e sustentabilidade: mecanismos de controle e resistência. Río de Janeiro: Terra Vermelha. 
Grupo de Trabalho Acadêmico Profissional Multidisciplinar. (2013). Villa Autódromo. Recuperado de http://lemetro.ifcs.ufrj.br/gtapm_ parecer_2013.pdf

Guimarães, R. C.V. (2015). Barra da Tijuca e o Projeto Olímpico: a cidade do capital (sustentación de maestría). Universidad Federal de Río de Janeiro, Brasil.

Konchinsk, V. (15 de abril del 2014). Obra de avenida olímpica derrubará 200 mil m$^{2}$ de Mata Atlântica no Rio. UOL Sporte. Recuperado de https://esporte.uol.com.br/rio-2016/ultimas-noticias/2014/04/15/ obra-de-avenida-olimpica-do-rio-vai-derrubar-200-mil-m-de-mataatlantica.htm

Ley Complementaria 111 de $1^{\circ}$ de febrero. (2011). Dispões sobre a Política Urbana e Ambiental do Município, Institui o Plano Diretor de Desenvolvimento Urbano Sustentável do Município do Rio de Janeiro e dá Outras Providências. Recuperado del sitio de internet de la Prefectura de Río de Janeiro: http://www.rio.rj.gov.br/dlstatic/10112/139339/ DLFE-229591.pdf/LeiComplementar1112011PlanoDiretor.pdf

Lussault, M. (2007). L'homme spatial. La construction sociale de l'espace humain. París: Editions du Seuil.RioOnWatch. (2016). A Realidade dos Moradores do Parque Carioca Após Reassentamento da Vila Autódromo: Relatos das favelas cariocas. Recuperado de http:// rioonwatch.org.br/?p=20108Rio Prefeitura (2013). Proyecto Parque Carioca [diapositivas de Power Point]. Recuperado de http://www.rio. rj.gov.br/dlstatic/10112/3641881/DLFE-267980.pdf/Apresentacao_ Parque_Carioca_2.0.1.3.pdf

Prefeitura do Rio. (s. f.). Minha Casa, minha Vida. Recuperado de http:// www.rio.rj.gov.br/dlstatic/10112/3641881/DLFE-267980.pdf/ Apresentacao_Parque_Carioca_2.0.1.3..pdf

Sanchez, F. (2009). A (in) sustentabilidade das cidades-vitrine. En Acserald, H. (org.), A duração das ciudades: sustentabilidade e risco nas políticas urbanas (2.a ed.) (pp. 171-192). Río de Janeiro: Lamparina. 
Smith, N. (2006). A gentrificação generalizada: de uma anomalia local à "regeneração" urbana como estratégia urbana global. En Bidouzachariasen, C. (org.), De volta à cidade: dos processos de gentrificação às políticas de "revitalização" dos centros urbanos. São Paulo: Annablume.

Vainer, C. B. (2000). Pátria, empresa e mercadoria: notas sobre a estratégia discursiva do Planejamento Estratégico Urbano. En O. B. F. Arantes, C. B. Vainer e E. Maricato (orgs.), A cidade do pensamento único: desmanchando consensos (pp. 75-103). Petrópolis: Vozes. 
